\title{
O LUGAR DA MÚSICA NO ESPAÇO DO CUIDADO TERAPÊUTICO: SENSIBILIZANDO ENFERMEIROS COM A DINÂMICA MUSICAL ${ }^{1}$ THE PLACE FOR MUSIC IN THERAPEUTIC CARE: SENSITIZING NURSING WITH THE MUSICAL DYNAMIC
}

\section{EL LUGAR DE LA MÚSICA EN EL ESPACIO DEL CUIDADO TERAPÉUTICO: SENSIBILIZANDO A LOS ENFERMEROS CON LA DINÁMICA MUSICAL}

\author{
Leila Brito Bergold?, Neide Aparecida Titonelli Alvim³, Ivone Evangelista Cabrat
}

\begin{abstract}
Trabalho desenvolvido em 2004 no espaço da disciplina "Oficina de Análise Institucional, Práticas Artísticas e Produção do Conhecimento", oferecida pelo Curso de Mestrado em Enfermagem da Pós-Graduação da Escola de Enfermagem Anna Nery (EEAN) da Universidade Federal do Rio de Janeiro (UFRJ), sob a responsabilidade das doutoras Ivone Evangelista Cabral e Neide Aparecida Titonelli Alvim.

${ }^{2}$ Enfermeira. Musicoterapeuta do Hospital Central do Exército do Rio de Janeiro. Mestre pelo Núcleo de Pesquisa de Fundamentos do Cuidado de Enfermagem (NUCLEARTE) da EEAN/UFRJ.

${ }^{3}$ Professora Adjunto do Departamento de Enfermagem Fundamental da EEAN/UFRJ. Doutora Pesquisadora Membro da diretoria do NUCLEARTE.

${ }^{4}$ Professora Adjunto do Departamento de Enfermagem Materno-Infantil da EEAN/UFRJ. Doutora. Pesquisadora do Núcleo de Enfermagem Saúde da Criança (NUPESC). Pesquisadora do CNPq. Membro do Corpo Docente da Pós-Graduação da EEAN e Núcleo de Tecnologia Educacional para a Saúde (NUTES)/UFRJ.
\end{abstract}

PALAVRAS-CHAVE: Música. Enfermagem. Tecnologia. Empatia. Terapêutica.

KEYWORDS: Music. Nursing. Technology. Empathy. Therapeutics.

PALABRAS CLAVES: Musica. Enfermería. Tecnología. Empatía. Terapéutica.

RESUMO: As influências da música no corpo foram objeto deste estudo conduzido junto a um grupo de enfermeiros participantes de uma disciplina de Pós-Graduação. Além de descrever essas influências, o estudo objetivou analisar a aplicabilidade da dinâmica de criatividade e sensibilidade (DCS) CorpoMusical como forma de sensibilização do enfermeiro quanto ao uso da música na sua prática de cuidarensinar. Utilizou-se o Método Criativo-Sensível e o desenvolvimento da DCS na produção de dados da pesquisa. As influências holística, lúdica e mecânica da música sobre o corpo foram os temas gerados na discussão. O grupo concluiu que a música age sobre todo o corpo, mas cada estilo estimula mais determinada região. Sua influência está na dependência do contexto, estilo musical e gosto do ouvinte. A pesquisa revelou o potencial da dinâmica como rico espaço de educação dialógica, constituindo-se como estratégia importante na sensibilização dos enfermeiros sobre as possibilidades da música como recurso terapêutico.

ABSTRACT: The influences of music on the body were the object of this study developed along with a group of nurses in a Graduate discipline. Besides describing these influences, the study's objective is to interpret the applicability of the dynamic of creativity and Body-Musical sensitivity as a way to make the nurse create sensitiveness when it comes to music in the care process. The Creative-Sensitive Method has been used in the production of research data. The holistic, frolic, and mechanical influences of music on the body were the themes discussed. The group concluded that music acts on the whole body and its influence depends on the context, music style, and listener taste. The research revealed the potential of this dynamic as a wide space of dialogical education, consisting in an important strategy in the action of the nurses about music possibilities as a therapeutic resource.

RESUMEN: Las influencias de la música en el cuerpo, fueron objeto de este estudio conducido junto a un grupo de enfermeros participantes de una disciplina del Posgrado. El estudio tuvo como objetivo, analizar la aplicabilidad de la Dinámica de Creatividad y Sensibilidad Cuerpo-Musical como una forma de sensibilización del enfermero respecto al uso de la música en su práctica de cuidar. Se utilizó el Método Creativo-Sensible y el desarrollo del DCS en la producción de datos de investigación. La influencia holística, lúdica, y mecánica de la música sobre el cuerpo, fueron los temas generados en la discusión. El grupo concluye que la música reacciona sobre todo el cuerpo pero influye según el estilo musical para una determinada región gusto del oyente. La investigación reveló el potencial de la dinámica como un rico espacio de la educación dialógica, constituyéndose como una estrategia importante en la sensibilización de los enfermeros, sobre las posibilidades de la música como un recurso terapéutico.

Endereço: Leila Brito Bergold Av. Rui Barbosa 20, Ap. 1001 22.250-020 - Flamengo, Rio de Janeiro, RJ.

E-mail: leilabergold@terra.com.br
Artigo original: Pesquisa Recebido em: 22 de novembro de 2005. Aprovação final: 27 de abril de 2006. 


\section{INTRODUÇÃO}

A música, ao se constituir como expressão artística e cultural importante e universal, produz trilhas sonoras que embalam o cotidiano da vida social, afetiva e profissional das pessoas, além de favorecer a manutenção da saúde mental, a prevenção do estresse e o alívio do cansaço físico. A constatação, cada vez mais freqüente, do poder de mobilização emocional da música nos leva a refletir sobre sua utilização para promover bem-estar e integração em diferentes âmbitos, especialmente, neste estudo, no campo do educar-cuidar em enfermagem.

$\mathrm{O}$ interesse da enfermagem pela música como um recurso no cuidado tem aumentado e pode ser constatado nos estudos que apontam suas diversas contribuições junto ao cliente, a exemplo de trazer conforto, diminuir a dor, facilitar a comunicação e a relação cliente-enfermeiro, tornando o cuidado mais humanizado. ${ }^{1} \mathrm{O}$ êxito dessas experiências nos faz acreditar na importância de sensibilizar os enfermeiros quanto à possibilidade do uso da música na sua prática do cuidar, considerando que "a música, assim como o cuidado, não devem ser vistos como prerrogativas de uma determinada profissão, mas sim de qualquer profissional da saúde que, no atendimento ao cliente, esteja preocupado em fazê-lo de forma respeitosa, com conhecimento científico e valorizando a construção de subjetividades inerentes ao afeto e à criatividade". 2:1

Contudo, não devemos nos ater somente a experiências musicais voltadas para o cuidar-ensinar da enfermagem junto ao cliente, mas refletir também sobre a possibilidade de ampliar a utilização da música para a formação do enfermeiro, na prática de ensinoaprendizagem, procurando estimular nos estudantes o pensamento crítico-reflexivo baseado em uma maior percepção de si próprio e de sua relação com o seu contexto. Nesse sentido, como a experiência que temos do mundo é basicamente emocional, "a música, essa forma de conhecimento humano com tonalidade afetiva, adquire também força educacional, haja vista a educação não se resumir à simples transmissão de conhecimentos, e sim, mais que isso, se caracterizar como um processo de desenvolvimento de sentidos e significados em que o educando, refletindo o mundo em volta, transforma a ele próprio" 3:131-2

Tendo isso em vista, consideramos a possibilidade de pesquisar a utilização de uma dinâmica musical para despertar a escuta sensível como importante ferramenta para a aprendizagem, para a pesquisa e para a comunicação enfermeiro-paciente. A observação re- alizada com a dominância do olho na captação de impressões sensíveis corre o risco de incorporar impressões parciais do objeto sob investigação. A especialização visual tende a separar, dividir o espaço, mantendo as coisas à distância. Já a escuta aproxima, pois o observador necessita estar próximo para escutar, ele ouve o que lhe interessa, mas ouve também o que interessa ao outro. Por isso é necessário desenvolver a escuta sensível, apurando a capacidade de ouvir, sentir e perceber. É importante também o despertar sensorial através do resgate dos sentidos para a promoção de uma crítica sensível que traga contribuição à produção do conhecimento em enfermagem. ${ }^{4}$

A influência da música sobre o corpo foi objeto deste estudo conduzido junto a um grupo de enfermeiros participantes (professoras, alunos e alunas) de uma disciplina de Pós-Graduação da Escola de Enfermagem Anna Nery, Universidade Federal do Rio de Janeiro. Além de descrever essa influência, o estudo teve também por objetivo discutir a aplicabilidade de uma Dinâmica de Criatividade e Sensibilidade (DCS) como forma de sensibilização do enfermeiro para a utilização da música na prática do educar e do cuidar. A nossa pergunta era: "de que forma a dinâmica musical pode sensibilizar o(a) enfermeiro(a) para a utilização da música no espaço do educar-cuidar em enfermagem"?

\section{DESCRIÇÃO METODOLÓGICA}

A pesquisa qualitativa foi implementada através do Método Criativo e Sensível (MCS) e consistiu na adaptação da DCS “Corpo-Saber". ${ }^{5}$ Diversos métodos de pesquisa utilizam dinâmicas para sensibilizar os participantes, seja com o objetivo de promover o contato destes com sua subjetividade, seja como técnica de mobilização grupal. No MCS, a criatividade e a sensibilidade são valorizadas na produção de dados da pesquisa e as dinâmicas têm por objetivo facilitar a expressão dos sujeitos da pesquisa e evitar a dicotomia entre razão e emoção. ${ }^{6}$ Este método aglutina sensibilidade com discurso teórico, através de idéias coletivas e da linguagem artística, valorizando a dimensão social e coletiva do conhecimento. Combina ciência e arte ao aliar técnicas de coleta de dados já consolidadas na pesquisa qualitativa, como a entrevista coletiva, a discussão grupal e a observação participante, com as DCS, eixo norteador do método. O propósito fundamental é aguçar a expressão da subjetividade dos participantes da pesquisa, além de proporcionar a interação entre o grupo e a pesquisadora. ${ }^{5}$ 
Nessas dinâmicas são utilizados materiais e atividades que permitem a expressão da criatividade dos participantes. As discussões de grupo, possibilitadas pela apresentação das produções artísticas geradas nas DCS, são desenvolvidas em uma perspectiva dialógicodialética, fundamentada na pedagogia crítico-reflexiva, pois esse espaço de discussão grupal é o momento no qual o grupo supera a condição de objeto e passa a ser sujeito do conhecimento produzido. ${ }^{7}$

A dinâmica desenvolvida nesta pesquisa, "Corpo-Musical", tinha por finalidade servir como testepiloto para uma dissertação de mestrado em andamento, ${ }^{1}$ e estimulou a focalização da influência da música no corpo para auxiliar a expressão da subjetividade de cada participante envolvido na experiência musical. A silhueta de um corpo físico foi desenhada em uma folha de papel craft, com caneta de cor intensa, e mantida fixa ao chão. Nessa silhueta, os participantes registraram como a música se expressava em seu corpo, a ação e reação do corpo aos diferentes estilos musicais selecionados para o encontro.

A principal tarefa era localizar nas partes do corpo a influência que cada musica produzia sobre ele. À medida em que a música era absorvida pelo corpo, os participantes registravam sua ação como promotora de relaxamento, excitação ou estimuladora de lembranças. Nessa perspectiva, teve-se em conta que existência e corpo formavam uma só realidade. Foram as experiências vividas pelos sujeitos dentro de um contexto histórico e cultural que buscamos durante a dinâmica "Corpo-Musical", pois a música estimula o resgate dessas experiências.

Tendo em vista a materialização da subjetividade dos participantes da pesquisa, a dinâmica "CorpoMusical" estimulou a discussão entre eles acerca da percepção musical, gerando um debate que promoveu a crítica reflexiva de suas concepções sobre a música e de suas possibilidades como recurso terapêutico, tanto na perspectiva pessoal quanto educacional e profissional. Tanto a produção artística, localizada na silhueta desenhada, quanto a discussão grupal realizadas pelos sujeitos serviram como base de dados para esta pesquisa.

A implementação desta dinâmica aconteceu em uma etapa somente, no espaço de um Laboratório de Práticas de Ensino, dotado de condições estruturais viabilizadoras da pesquisa que incluíram climatização, cadeiras e almofadas adequadas, além de aparelho de som, folhas, canetas, cola e outros materiais disponíveis para a produção artística.
Reuniu-se um grupo de 11 enfermeiros (9 alunos e 02 professoras) que, por 90 minutos, desenvolveu os passos da dinâmica. A equipe que coordenou a atividade de pesquisa constituiu-se por 3 pessoas desse grupo: uma coordenadora, na qualidade de moderadora; uma observadora, responsável pelo registro do movimento do corpo e do diálogo entre os participantes; e uma responsável pelo apoio logístico (colocar os CDs com as músicas selecionadas e distribuir o material a ser usado pelos participantes). Os sujeitos da pesquisa foram 7 enfermeiros desse mesmo grupo, de ambos os sexos e idades variadas, com prática profissional em diferentes áreas: assistencial, administrativa, ensino e pesquisa. A última participante do grupo, uma das professoras, ficou com a função de supervisionar todo o processo.

Foram respeitados os aspectos éticos da pesquisa dispostos na Resolução 196/96, do Conselho Nacional de Saúde/MS, que regula as Normas de Pesquisa envolvendo Seres Humanos. Além da autorização do Comitê de Ética em Pesquisa da Instituição, cenário do estudo, os participantes assinaram o termo de consentimento livre e esclarecido. Ainda em observância à mencionada Resolução, mantivemos o anonimato dos sujeitos da pesquisa.

\section{ETAPAS DA DINÂMICA DESENVOLVIDA}

\section{Exercício de relaxamento introdutório à temática}

Não foi necessário realizar nesta primeira etapa a apresentação dos participantes, pois todos já se conheciam previamente. Solicitamos que sentassem o mais confortavelmente possível, sugerindo que o fizessem nas almofadas, em círculo, para que pudessem ficar próximos à silhueta desenhada colocada ao centro. Optamos por realizar relaxamento a partir de uma indução verbal com o intuito de focalizar a atenção dos participantes em seu próprio corpo naquele momento, levando-os a tomarem consciência de seus corpos e preparando-os para a audição das músicas e a percepção dos efeitos destas sobre si mesmos.

\section{Exposição sobre a dinâmica}

Explicamos aos participantes que deveriam se concentrar na escuta de cada música tocada, observando que influências estas exerceriam sobre eles. Ao final de cada música, eles anotariam em um papel adesivo o que haviam percebido ou sentido e colariam na silhueta de um corpo que havia sido desenhada em 
papel pardo antes do início da dinâmica. Deveriam colar este papel na parte do corpo que sofreu a influência da música. Nesse momento, também foi exposta a questão geradora de debate: "de que forma a música influencia o seu corpo?"

\section{Produção artística}

Apresentamos três músicas de estilos bem diferenciados: música clássica, chorinho e rock. Buscamos estímulos bastante diversificados para facilitar a comparação entre as percepções de cada música para os participantes. Como o objetivo principal era focalizar sua influência, optamos por não apresentar músicas que contivessem letras, ou, como no rock, que fosse em língua estrangeira, dificultando, assim, a indução de sentimentos ou idéias trazidas pelas palavras. As músicas foram tocadas em ordem de progressão rítmica, indo da mais "calma" para a mais "agitada". No início de cada execução musical foram entregues aos participantes folhas auto-colantes de diferentes cores para caracterizar melhor a sua distribuição na silhueta desenhada. Para a música clássica a cor do papel foi rosa, para o chorinho foi utilizada a cor verde-limão e para o rock, um papel branco. Nessa etapa, todos mostraram-se bastante concentrados na atividade proposta, havendo pouca comunicação verbal entre os participantes.

\section{Apresentação da produção artística pelos su- jeitos, seguida de debate}

Após todos haverem escrito e colado os papéis adesivos, iniciou-se a apresentação da produção, quando cada participante falou sobre o que escreveu e explicou as razões que o levaram a colar os papéis adesivos em determinada parte do corpo. Nessa etapa, os participantes, em sua maioria, mostraram-se bastante motivados para comentar as sensações, sentimentos e lembranças estimulados pelas músicas. Da apresentação, derivou-se naturalmente a discussão grupal, pois todos queriam falar sobre as semelhanças e diferenças percebidas a partir do relato de cada um. No movimento dialógico, que oportunizou o entrelaçamento das vivências e experiências musicais dos sujeitos e de como a música faz parte de seu cotidiano, emergiu a crítica reflexiva do grupo sobre o lugar que a mesma ocupa (ou pode ocupar) no espaço do educar e no cuidar em enfermagem.

\section{Síntese da análise e validação coletiva}

A validação coletiva no contexto das DCS é uma etapa fundamental para assegurar a confiabilidade dos dados produzidos. Nela, o pesquisador tem a possibilidade de negociar com os sujeitos da pesquisa a sua compreensão sobre o material produzido, analisado e discutido nas etapas anteriores. A interpretação dos dados, etapa posterior a realização do trabalho de campo, é conduzida com maior fidedignidade a experiência, significação e menor risco de leituras transversais. Isso é possível, porque no âmbito de as DCS “o próprio grupo vai confirmando o que é comum e particularizando o incomum", 6:178 o que permite validar os dados produzidos em seu interior. Assim, ao final da discussão, buscou-se a síntese do que havia sido discutido em um movimento que focou tanto a singularidade quanto a pluralidade como características essenciais da discussão grupal.

Para analisar os dados optamos pela análise de discurso visto que esta trabalha com os processos de constituição dos sujeitos e dos sentidos, ${ }^{8}$ sendo apropriada para a compreensão dos sentidos produzidos durante a dinâmica.

\section{RESULTADOS}

Os participantes da pesquisa perceberam que as músicas tocadas provocaram diferentes reações, não só por serem três estilos distintos, mas porque cada um produziu respostas ligadas às singularidades dos sujeitos. As influências holística, lúdica e mecânica foram os temas geradores de debate que emergiram do processo de codificação (representação de uma situação existencial que, nesse caso, foi expressa através das produções artísticas), descodificação (transição dessa situação para o concreto a partir da discussão crítica desta em seu contexto real) e recodificação temática (síntese grupal, ou seja, quando houve a validação do que foi discutido).

\section{Influência holística}

A primeira música tocada foi do tipo clássico, executada por instrumentos de cordas (violino e violoncelo) com características mais melódicas e harmônicas e de pouca ênfase no ritmo. Foi escolhida por ter andamento lento, diferente de outras músicas clássicas que, devido à intensidade dos sons, ou, ao andamento mais rápido ou marcado, são mais estimulantes do que relaxantes. A música escolhida foi descrita por

*Clássica: Cânon em Ré Maior (Pachelbel). Chorinbo: Sorriso de Cristal (Érika Rego). Rock: Paranoid (Oz:y Osborne e Tony Iommi).

Texto Contexto Enferm, Florianópolis, 2006 Abr-Jun; 15(2):262-9. 
todos os participantes como relaxante, sendo observado que os que inicialmente tiveram dificuldade para relaxar durante a indução verbal demonstraram relaxar ao escutá-la.

A resposta emocional provocada pela música depende da percepção de parâmetros de andamento e modo, sendo o modo "a série de notas sucessivas organizadas segundo um padrão de intervalos definido, diferindo o padrão de um modo a outro - menor e maior. O grau de velocidade que se imprime à execução de um trecho musical define o andamento". 9:54 Dessa forma, músicas do tipo lento e modo maior (características desta primeira música) podem induzir à serenidade. ${ }^{9}$ Outro parâmetro situa-se na música tranqüilizante que está relacionada a tempos regulares e harmonia. Músicas que comportam disparidades de ritmo e dissonâncias (acordes que criam forte tensão, tornando-se instáveis para o ouvinte) seriam mais estressantes. ${ }^{10}$

Através da produção artística os participantes mostraram que a influência da música clássica se fez presente na totalidade do corpo, embora com maior concentração na região da cabeça e do tórax. Alguns efeitos descritos pelos participantes incluíram suavidade, choro, riso, canto, tranqüilidade. Foram discriminadas também a narina, a boca e a mão, interligando outros sentidos nessa percepção musical. Dois participantes relacionaram a palavra "dança" às pernas, ou seja, apesar de ser relaxante, a música clássica também impelia a movimentos de dança.

Refletimos que se, por um lado, houve um consenso quanto ao efeito relaxante deste estilo musical, por outro, encontramos uma diversidade de reações que nos impeliu a buscar outras visões sobre a percepção musical. Os humanos percebem a música como algo a mais do que simples som. Ela provoca percepção visual, atividade motora sensorial, processamento de informação abstrata e simbólica, assim como a expressão de diferentes emoções. O cérebro de cada pessoa processa a música de uma determinada forma, de acordo com o foco do ouvinte e sua experiência, sendo difícil encontrar regras universais. Ou seja, se, de um lado, todos relataram relaxar com esta primeira música, de outro, este relaxamento processou-se de forma particular para cada pessoa. ${ }^{11}$

Mais de um participante se referiu ao pulmão e às costas. Sabemos da importância da respiração para a promoção do relaxamento, sendo que exercícios respiratórios são muito utilizados em diversas técnicas para que a pessoa entre em contato consigo mesma, liberando as tensões externas. Um dos participantes percebeu que a sua freqüência respiratória havia diminuído ao escutar a música clássica, sentindo-se mais relaxado após o plantão noturno, que havia desenvolvido na noite anterior. Encontramos, assim, um Encontramos, assim, uma conexão entre a audição musical e o relaxamento corporal que pode estar relacionada à diminuição da freqüência respiratória, fato que merece aprofundamento em outras investigações.

Durante a discussão grupal, alguns referiram usar a música clássica com freqüência, para relaxar e/ou estudar. A música apresenta possibilidades psicopedagógicas, pois influencia a atenção, a memória, o desenvolvimento do pensamento lógico e a maturação intelectual. ${ }^{3}$ Refletimos também sobre a possibilidade de o relaxamento facilitar a concentração necessária à atividade do intelecto. Um dos participantes referiu que esse tipo de música estimula sua criatividade. A capacidade de criar necessita de integração entre percepção, emoção e racionalidade, e podem ser estimuladas pela experiência musical, na medida em que "a emoção estética transcende a pura experiência sensorial, assentando-se numa maior discriminação intelectual, encontramos aí um auxiliar valioso para o desenvolvimento da equação pessoal do educando [...] a música desenvolve a sensibilidade, favorece a disciplina e contribui para o desenvolvimento da consciência de cidadania do educando". 3:64-5 Portanto, a música pode ser utilizada tanto como recurso de ensino-aprendizagem do enfermeiro, quanto na sua ação educativa junto ao cliente cuidado.

Para que uma música aja como estimulante ou relaxante é necessário que o ouvinte estabeleça algum tipo de conexão com ela. Esta possibilidade de conexão é influenciada pelo universo musical da pessoa, que, por sua vez, está inserida em um determinado contexto e cultura. Um exemplo dessa conexão foi constatado pela observadora da dinâmica ao perceber que um participante, que relatou sempre estudar com música clássica, foi o primeiro a terminar sua produção após escutar este gênero. Em contrapartida, ao ouvir o chorinho não conseguiu escrever uma só palavra, o que nos levou à reflexão de que diferentes gêneros musicais podem provocar distintas ações e reações no ouvinte.

O chorinho escolhido tem a predominância do som do saxofone que executa a melodia com um toque de sensualidade, acompanhada por violão, baixo e piano, tendo o ritmo marcado executado por uma bateria. A influência holística também foi percebida no chorinho, pois este se mostrou melhor distribuído no corpo do 
que a música clássica, e as reações dos participantes demonstraram sua articulação com a ludicidade.

\section{Influência lúdica}

Durante a audição do chorinho, a observadora percebeu que as pessoas mostraram-se mais descontraídas e sorridentes, realizando movimentos corporais (balançar o corpo e batucar com as mãos). Percebeu também o esboço de sorrisos e que o desenvolvimento da produção se acelerou. A palavra de destaque nos escritos da produção dos participantes, situada nas partes da silhueta do corpo foi "dançar", mas os sujeitos da pesquisa também relacionaram outras palavras: alegria, sorriso, emoção, batucar com as mãos, dança, festa, nostalgia. O chorinho fazia parte do universo musical de quase todos os participantes, conectando-os a sentimentos positivos, ligados à sensação de prazer e diversão.

Esse momento lúdico estimulou a comunicação entre os participantes, levando-os a trocar olhares ou rápidos comentários, apontando a possibilidade de integração promovida pela música. Em pesquisa recente, essa qualidade integradora da música e suas possibilidades lúdicas também foram evidenciadas na discussão grupal com clientes internados, quando se abordou a atividade musical na promoção da comunicação e da interação no ambiente hospitalar. ${ }^{1}$

O momento lúdico promovido pela música pode ser um recurso importante não somente para o cuidado com o outro, mas para o autocuidado ao promover relaxamento, bem-estar e prazer de estar consigo mesmo e com o outro. A busca do prazer e a preocupação com a qualidade de vida são valorizadas à medida que favorecem o desejo do outro, o que permite explorar o potencial nas diversidades e pluralidades de trocas com o meio, ampliando a visão do que se considera um sistema de cuidado. ${ }^{12}$

A produção artística apontou uma forte concentração de adesivos nos membros inferiores, cujo efeito estava ligado ao desejo de se movimentar ou dançar. Foi a única música que concentrou adesivos colados na região dos quadris. Relacionamos este fato, não só ao desejo de dançar, mas também à sensualidade inerente ao ritmo sincopado do chorinho, semelhante ao ritmo do samba, que desperta a vontade de movimentar o corpo da cintura para baixo, especialmente, os quadris.

Durante a discussão grupal, um dos participantes que reside em outro estado relacionou a música a lembranças do Rio de Janeiro e à dança. A lembrança despertada pode estar ligada a experiências vivenciadas na cidade, ou, pela relação que as pessoas fazem entre ela e essa cidade, local de surgimento do chorinho no final do séc. XIX. ${ }^{13}$ Tempo e lugar estão intimamente relacionados através da experiência musical e ao escutarmos músicas que estão ligadas à nossa história revivemos lembranças, impressões e emoções relacionadas aos eventos significativos de nossa vida. ${ }^{2}$

Ao escolhermos o último estímulo musical, optamos por um estilo que contrastasse com os anteriores, criando um impacto, o rock. Nesse sentido, procuramos um rock mais "pesado", com ritmo pronunciado, guitarras distorcidas e vozes gritadas. Logo no início da execução da música alguns participantes riram, achando engraçado esse tipo de música naquele contexto, mas a discussão grupal revelou que, ao contrário da sensação lúdica, o rock trouxe desconforto à maior parte dos participantes e os fez associar este estímulo a movimentos mecânicos do corpo.

\section{Influência mecânica}

As reações ao rock foram antagônicas. Um dos participantes sorriu e demonstrou um brilho diferente no olhar, outro tentou batucar, um terceiro mostrouse agitado relatando, posteriormente, que sentiu as freqüências respiratórias e cardíacas se acelerarem naquele momento. Houve um que começou a mexer a cabeça ritmicamente e outro participante logo reclamou, demonstrando nitidamente um forte incômodo. Durante a discussão, relatou ter tido uma experiência ruim com um vizinho adolescente que escutava rock muito alto.

É importante destacar o relato de outro participante que, ao contrário do anterior, revelou que essa música lhe trazia recordações de primos a quem queria muito bem, lembrando-lhe experiências prazerosas referentes à convivência durante a adolescência. Assim, a música, ao estimular a produção de subjetividades, traz a singularidade de cada pessoa à tona, suas vivências pessoais, familiares e culturais. Por isso devemos estar atentos a como cada um percebe determinada música em um momento específico, pois é variável o nível de tolerância pessoal a um determinado estímulo sonoro, “a qualidade das respostas é que vai determinar se o som está sendo utilizado de forma correta ou incorreta". ${ }^{4: 53}$

Excetuando a experiência positiva revelada pelo mencionado participante, os outros relataram desconforto, agitação, confusão, incômodo, sendo concebido como um estímulo ruim e desagradável. Um dos par- 
ticipantes comentou que mexeu a cabeça porque essa música é "bate-estaca" (em um sentido pejorativo). Apesar de não sentirem prazer ao escutarem a música, a maior parte dos participantes realizou movimentos mecânicos, mostrando a força do ritmo sobre eles.

Essa falta de conexão com o rock parece indicar, como dissemos, que este não fazia parte do universo sonoro de grande parte do grupo. O rock é um gênero mais ligado à afirmação da identidade da juventude, lidando de forma direta com a sexualidade e agressividade inerentes a esta fase. ${ }^{3}$ Isso não corresponde ao momento de vida atual dos sujeitos da pesquisa, pois, além de pertencerem à outra faixa etária, o perfil profissional da enfermagem aponta a necessidade de relaxamento, devido à intensa atividade motora e tensão que envolve a sua prática profissional.

$\mathrm{Na}$ produção realizada na silhueta, o rock também se concentrou mais na cabeça e peito, sendo que dois participantes escreveram "raiva" e outros dois "sorriso", denotando sentimentos antagônicos que esta música despertou. Apesar de se constituir como música ritmada, poucos colaram papéis na região das pernas, que poderiam indicar movimento. O inusitado é que três participantes colaram papéis fora da silhueta com as expressões: "bagunça", "malhar" e "descarregar energia pulando", como se essa música extrapolasse o espaço do corpo físico, ou como se não se conseguisse uma conexão com o indivíduo ficando como estímulo estritamente externo. Durante a discussão, alguns o relacionaram às academias de ginástica, onde as músicas ritmadas são utilizadas para estimular movimentos mecânicos.

\section{Síntese grupal: a percepção de si e do outro - a música como recurso no educar e no cuidar em enfermagem}

A recodificação temática produzida pelo grupo revelou o consenso de que a música age sobre todo o corpo, mas cada estilo estimula mais uma determinada região. O grupo percebeu também que houve maior concentração na região da cabeça por ser a parte do corpo que capta e "aprecia" primeiro a música. Embora a música promova diversas reações, seus efeitos não podem ser separados e devem ser vistos de forma global e complexa. ${ }^{3}$ Tornaram-se evidentes as possibilidades de relaxamento e ludicidade que algumas músicas podem proporcionar, ao tempo em que é preciso evitar alguns ritmos que evocam sentimentos negativos e que podem acarretar prejuízos de diversas naturezas ao ouvinte, tanto no âmbito pessoal quanto no profissional. Os sujeitos da pesquisa refletiram também que a música influenciou cada um de uma forma singular devido às implicações individuais, havendo diferenças na percepção e sentimentos de cada participante, reforçando o consenso de que a música facilita a produção de subjetividades evidenciando a singularidade de cada indivíduo.

No âmbito educacional, a música revelou-se como um recurso já utilizado pelos participantes para relaxar, estudar e estimular a criatividade. Durante a dinâmica também ficou evidenciada a sua qualidade de promover o auto-conhecimento, a reflexão e a percepção do outro, aspectos importantes para o desenvolvimento pessoal e a integração social, evidenciados também em outra pesquisa. ${ }^{1}$ Estes aspectos relacionados são fundamentais para o auto-crescimento do estudante e para ampliar a sua visão sobre o cuidar em enfermagem, incluindo-se neste cuidado as ações de caráter educativo. "A atividade de cuidar surge da criatividade humana, das sensibilidades frente às trocas com o outro e das condições naturais de capacidade do homem de criar novas situações...". 12:63

Nenhum dos participantes relatou usar a música diretamente na sua prática profissional. No entanto, alguns desses conhecem enfermeiros que têm buscado inserir a música na sua prática de educar-cuidar junto ao cliente. Pesquisa realizada com clientes que haviam sido internados em um Centro de Terapia Intensiva (CTI) mostrou que estes tiveram opiniões divergentes: alguns foram contra qualquer tipo de música e outros afirmaram que só seria aceitável música gravada, suave e instrumental. ${ }^{14} \mathrm{O}$ fato em questão é que o cliente deve ser a principal prioridade e não a música. Assim, se esta não fizer parte do universo sonoro dos clientes pode funcionar como mais um fator estressante. $^{2}$

Outra pesquisa realizada em CTI constatou que o uso de música ao vivo, cantada e acompanhada por violão foi bem aceita pelos clientes internados, sendo um valioso instrumento no processo de humanização e uma alternativa criativa e eficaz no alívio da dor. Em relação à equipe, os benefícios percebidos vão desde a prevenção do estresse, tratamento de níveis de tensão e desgaste psicológico, até o maior comprometimento com as atividades profissionais e integração social. ${ }^{15}$

Se as pesquisas ainda não são conclusivas quanto à forma mais adequada de utilizar a música terapeuticamente, é importante que cada enfermeiro possa refletir, com base na sua própria experiência, como a música metaforicamente lhe "toca". Para isso, 
o desenvolvimento da dinâmica "Corpo-Musical" mostrou-se relevante como espaço de produção de dados da pesquisa baseada na percepção de si e do outro e na discussão grupal que levou à reflexão-crítica. Também se constituiu como estratégia importante na sensibilização dos enfermeiros participantes em relação às possibilidades da música seja como terapêutica no campo do educar-cuidar em enfermagem seja como recurso de ensino-aprendizagem, revelando o potencial desta dinâmica como um rico espaço de educação dialógica.

\section{CONSIDERAÇÕES FINAIS}

A crítica reflexiva acerca das diversas influências da música sobre o corpo e de suas potencialidades como parte do cuidado terapêutico aponta a perspectiva da utilização da música como um recurso no âmbito educacional. A utilização da dinâmica "Corpomusical", por suas características criativas e sensíveis, mostrou a importância de se respeitar a preferência do outro por determinado estilo musical. A discussão grupal revelou que essas influências ocorrem na totalidade do corpo - físico, biológico, social e emocional - expressas em diferentes ações e reações, positivas e negativas, por vezes, ambíguas, como: sensação de relaxamento, de alegria, de raiva, de conforto, de irritabilidade, de incômodo, de satisfação, do desejo de se movimentar e tantas outras.

Portanto, como foi discutido entre os enfermeiros no âmbito da DCS, vale ter em consideração que, quando se pensa no cuidado criativo da enfermagem e na possibilidade do uso da música nesse contexto, de modo a sustentar suas influências positivas, é preciso que reflitamos sobre o seu uso consciente de forma a mantermos uma atitude ética relacionada ao respeito à autonomia do cliente em desejar a presença da música no espaço terapêutico, sua escolha em determinados momentos e circunstâncias, bem como o seu gosto musical.

Em uma visão ampliada da educação atual, não basta uma formação que contemple somente ciências básicas e humanas, mas também a percepção da influência da arte, e em especial da música, na expressão da criatividade para a promoção da singularidade, imprescindível no mundo globalizado de hoje, além de poder ser um recurso importante para equilibrar e humanizar o processo educacional.

\section{REFERÊNCIAS}

1 Bergold LB. A visita musical como estratégia terapêutica no contexto hospitalar e seus nexos com a enfermagem fundamental [dissertação]. Rio de Janeiro (RJ): UFRJ/ EEAN; 2005.

2 Bergold LB, Sobral V. Music for care humanization. Online Brazilian Nursing [online]. 2003 Dec; 2 (3): [acesso em 2005 nov 06]. Disponível em: www.uff.br/nepae/ objn203bergoldsobral.htm

3 Sekeff ML. Da música, seus usos e recursos. São Paulo: UNESP; 2002.

4 Cabral IE. Contribuição da crítica sensível à produção do conhecimento em enfermagem [CD-ROM]. In: Anais do 11o Seminário Nacional de Pesquisa em Enfermagem; 2001 Mai 24; Belém, Brasil. Belém: ABEN-PA; 2001. p.13

5 Alvim NAT. Práticas e saberes sobre o uso de plantas medicinais na vida das enfermeiras: uma construção em espiral [tese]. Rio de Janeiro (RJ): EEAN/UFRJ; 1999.

6 Cabral IE. O método criativo e sensível: alternativa de pesquisa na enfermagem. In: Gauthier JHM, Cabral IE, Santos I, Tavares CMM, organizadores. Pesquisa em enfermagem: novas metodologias aplicadas. Rio de Janeiro: Guanabara Koogan; 1998. p.177-203

7 Freire P. Educação e mudança. 27a ed. Rio de Janeiro: Paz e Terra; 2003.

8 Orlandi EP. Análise de discurso: princípios e procedimentos. Campinas: Pontes; 2003.

9 Vieillard S. Emoções musicais. Viver Mente Cérebro. 2005 Jun; 13 (149): 52-7.

10 Khalfa S. Melodia para os ânimos. Viver Mente Cérebro. 2005 Jun; 13 (149): 70-3.

11 Altenmüller ET. Acordes na cabeça. Viver Mente Cérebro. 2004 Out; 13 (141): 24-9.

12 Erdmann AL. O sistema de cuidados de enfermagem: sua organização nas instituições de saúde. Texto Contexto Enferm. 1998 Maio-Ago; 7 (2): 52-69.

13 Dourado HA. Dicionário de termos e expressões da música. São Paulo: Editora 34; 2004.

14 Conde KC. Considerações acerca do uso indiscriminado do som e dos seus efeitos no homem. Rev Bras. Musicoterapia. 1997; 2 (3): 51-60.

15 Backes DS, Ddine SC, Oliveira CL, Backes MTS. Música: terapia complementar no processo de humanização de um CTI. Rev. Nursing. 2003 Nov; 66 (6): 35-42. 